\title{
Correction
}

\section{Correction: Physiologically Realistic and Validated Mathematical Liver Model Revels Hepatobiliary Transfer Rates for Gd-EOB-DTPA Using Human DCE-MRI Data}

\section{The PLOS ONE Staff}

The word "Reveals" is misspelled in the article title. The correct title is: Physiologically Realistic and Validated Mathematical Liver Model Reveals Hepatobiliary Transfer Rates for Gd-EOB-DTPA Using Human DCE-MRI Data. The correct citation is: Forsgren MF, Leinhard OD, Dahlström N, Cedersund G, Lundberg P (2014) Physiologically Realistic and Validated Mathematical Liver Model Reveals Hepatobiliary Transfer Rates for Gd-EOB-DTPA Using Human DCE-MRI Data. PLoS ONE 9(4): e95700. doi:10.1371/journal.pone.0095700

\section{Reference}

1. Forsgren MF, Leinhard OD, Dahlström N, Cedersund G, Lundberg P (2014) Physiologically Realistic and Validated Mathematical Liver Model Revels Hepatobiliary Transfer Rates for Gd-EOB-DTPA Using Human DCE-MRI Data. PLoS ONE 9(4): e95700. doi:10.1371/journal.pone.0095700
Citation: The PLOS ONE Staff (2014) Correction: Physiologically Realistic and Validated Mathematical Liver Model Revels Hepatobiliary Transfer Rates for GdEOB-DTPA Using Human DCE-MRI Data. PLoS ONE 9(7): e104570. doi:10.1371/ journal.pone. 0104570

Published July 31, 2014

Copyright: (๑) 2014 The PLOS ONE Staff. This is an open-access article distributed under the terms of the Creative Commons Attribution License, which permits unrestricted use, distribution, and reproduction in any medium, provided the original author and source are credited. 